\title{
Comparing oxytocin and cortisol regulation in a double-blind, placebo-controlled, hydrocortisone challenge pilot study in children with autism and typical development
}

\author{
Blythe A. Corbett ${ }^{1,2,3^{*}}$, Karen L. Bales ${ }^{4}$, Deanna Swain ${ }^{5}$, Kevin Sanders ${ }^{1}$, Tamara A. R. Weinstein ${ }^{4}$ and Louis J. Muglia ${ }^{6}$
}

\begin{abstract}
Background: Children with autism spectrum disorder (ASD) show marked impairment in social functioning and poor adaptation to new and changing contexts, which may be influenced by underlying regulatory processes. Oxytocin (OT) and cortisol are key neuromodulators of biological and behavioral responses, show a synergistic effect, and have been implicated in the neuropathological profile in ASD. However, they are rarely investigated together. The purpose of the pilot study was to evaluate the relationship between cortisol and OT in children with ASD under baseline and physiological stress (hydrocortisone challenge) conditions. Arginine vasopressin (AVP), structurally similar to OT, was also examined.
\end{abstract}

Methods: A double-blind, placebo-controlled, randomly assigned, crossover design was employed in 25 children 8-to-12 years with ASD $(N=14)$ or typical development $(\mathrm{TD}, N=11)$. A low dose of hydrocortisone and placebo were administered via liquid suspension. Analysis of variance (ANOVA) was used to examine the within-subject factor "Condition" (hydrocortisone/placebo) and "Time" (pre and post) and the between-subject factor "Group" (ASD vs. TD). Pearson correlations examined the relationship between hormone levels and clinical profile.

Results: There was a significant Time $\times$ Condition $\times$ Group interaction $F(1.23)=4.18, p=0.05$ showing a rise in OT during the experimental condition (hydrocortisone) and a drop during the placebo condition for the TD group but not the ASD group. There were no group differences for AVP. Hormone levels were associated with social profiles.

Conclusions: For the TD group, an inverse relationship was observed. OT increased during physiological challenge suggesting that OT played a stress-buffering role during cortisol administration. In contrast for the ASD group, OT remained unchanged or decreased during both the physiological challenge and the placebo condition, suggesting that OT failed to serve as a stress buffer under conditions of physiological stress.

While OT has been tied to the social ability of children with ASD, the diminished moderating effect of OT on cortisol may also play a contributory role in the heightened stress often observed in children with ASD. These results contribute to our understanding of the growing complexity of the effects of OT on social behavior as well as the functional interplay and differential regulation OT may have on stress modulation.

(Continued on next page)

\footnotetext{
* Correspondence: blythe.corbett@vanderbilt.edu

'Department of Psychiatry and Behavioral Sciences, Vanderbilt University,

PMB 40, 230 Appleton Place, Nashville, TN 37203, USA

${ }^{2}$ Vanderbilt Kennedy Center for Research on Human Development, Nashville,

TN, USA

Full list of author information is available at the end of the article
} 
(Continued from previous page)

Keywords: Oxytocin, Cortisol, Hydrocortisone, Autism, Hormone, Stress, Arginine vasopressin, Stress, Autism spectrum disorder, LHPA axis

Abbreviations: ADOS, Autism Diagnostic Observation Schedule; ASD, autism spectrum disorder; AVP, arginine vasopressin; HCORT, hydrocortisone challenge; IDS, Investigational Drug Service; LHPA, limbic hypothalamic pituitary adrenal axis; OT, oxytocin; SCQ, Social Communication Questionnaire; SRS, Social Responsiveness Scale; WASI, Wechsler Abbreviated Scale of Intelligence; TD, typical development

\section{Background}

While many children find social interaction stress reducing, children with autism spectrum disorder (ASD) often find social interaction stress-inducing [1-3]. An appropriate response of the primary stress system, the limbichypothalamic-pituitary-adrenal (LHPA) axis, is essential for biological, behavioral, and psychosocial well-being. Conversely, inappropriate responsivity of the stress system may result in impairments in development and contribute to a variety of endocrine, metabolic, autoimmune, psychiatric, and social disorders [4]. However, variations in stress threshold and underlying regulatory mechanisms may contribute to differences in responsivity. In regard to ASD, social stress may be highly influenced by contextual (e.g., peers [5]) and neurohormonal (e.g., oxytocin) factors [6].

Social behavior is complex and so too is the socioemotional profile of individuals with autism. Since Kanner's [7] earliest accounts of autism, a diverse set of social and emotional response patterns have been described. Yet, years later, the underlying mechanisms are elusive that may be contributing to the atypical social responses that are central to this disorder. The role of hormones is to assist in the regulation, drive, and adaptation of the individual to the dynamic internal and external environment, including the social world. Key hormones involved in the regulation of social and stress responses, specifically oxytocin (OT) and cortisol, are both implicated in the neuropathology of autism (e.g., [8-12]).

Cortisol is the primary glucocorticoid in humans released from the adrenal cortices following activation of the LHPA axis. The system can be activated by systemic stress (physical, context-independent, life-threatening) or processive stress (psychological, context-dependent, perceived threat) [13]. Cortisol maintains a diurnal pattern and produces a variety of effects throughout the body including influences on cardiovascular function, immunity, metabolism, and neurobiology [14], which collectively allow optimal adaptation to changing environmental demands. In addition to being involved in several vital biological processes and interactions, cortisol is central to the physiological response to physiological or perceived psychological stress [13, 15]. Importantly, the LHPA axis can be influenced by social variables that can enhance or diminish the stress response $[16,17]$, which is highly relevant for the study of ASD, a disorder marked by impairment in social cognition, communication, and interaction [18].

Current and ongoing research has shown that children with ASD demonstrate heightened stress to various benign and novel stimuli $[9,10,19-21]$ and natural social conditions $[1,22,23]$. However, there is significant variability in response patterns of cortisol in children with ASD, which led to a hypothesized Neuroendocrine Spectrum Model in which social and arousal patterns intertwine to form unique social stress profiles [2, 3]. The hyper-responsivity of the LHPA may contribute to increased anxiety, neophobia, or even chronic stress. In fact, associations have been reported between heightened cortisol levels and self-reported trait anxiety [22, 24, 25]. Collectively, research shows that physiological arousal in ASD is on a continuum of responsivity [26] and can affect social interaction patterns $[1,3,5]$.

Due to the known deleterious effects of frequent and prolonged exposure to cortisol on mental and physical well-being, continued study in persons with ASD who evidence dysregulation of the LHPA axis is warranted. Moreover, the significant variability in cortisol suggests underlying differences in physiological response patterns that may be linked to neurohormonal crosstalk. It is highly plausible that cortisol, as an important modulator of biobehavioral functioning, may provide important clues as to associations with other key regulatory neurohormones, including OT, that contribute to social stress in autism.

$\mathrm{OT}$ is a hypothalamic peptide crucial to the formation of social bonds [27] (for a review, see [28]. Research in animal (e.g., [12, 29-32]) and human models [33-35] provides compelling evidence for the involvement of OT in mediating complex social behavior. OT plays an important role in stress buffering by reducing the responsiveness of the LHPA axis [33, 34, 36, 37]. Specifically, it appears that OT is an important moderator of stress by, in part, reducing activation of the medial amygdala [38] and modulating activation of the amygdala in response to facial expressions [39], which has been found to be dysregulated in autism [40-44].

In humans, OT facilitates social approach and provides anxiolytic effects [45], especially when combined with social support as shown in studies comparing intranasal OT vs. placebo $[46,47]$. This blunting effect appears 
short-term and specific to cortisol response [48]. Ostensibly, OT can reduce the responsivity of the LHPA axis to social stress by reducing uncertainty [39] and enhancing trust $[40,49,50]$, resulting in more social approach [51]). Further, OT may restrict the LHPA by making arginine vasopressin (AVP) less reactive [52] and buffer the vasopressin-ACTH-cortisol response [53]. For some stressors, OT has been shown to reduce corticotropic releasing hormone gene expression in the paraventricular nucleus, leading to reduction in ACTH and cortisol [54]. The results support the hypothesis that OT is a key moderator of social behavior and regulator of stress reactivity $[27,55]$. Although the results to date supporting a reciprocal relationship between $\mathrm{OT}$ and stress are compelling, some findings suggest that the interplay is complex and influenced by individual differences $[47,56]$ and social distress [57]. One of the roles of OT may be to motivate people to find positive social affiliations [57]. Thus, OT is influenced by individual factors associated with social affiliation and distress [58].

The neuropeptide OT has been associated with the neurobiology of autism [8, 12, 59-64]. Individuals with autism reportedly have impaired OT processing, resulting in higher levels of plasma OT-X, a precursor to the normal adult form of OT, and lower levels of OT [65-68]. In one study, elevated OT was associated with more sociality in typically developing children but was associated with less social behavior in children with autism, especially those characterized as aloof. [67] Several studies have shown genetic associations between the oxytocin receptor gene (OXTR) and autism [60, 69-75].

Recent reports suggest that OT may be a novel therapeutic target for treating social impairments of autism [58, 76-80]. OT treatments have been shown to increase the ability of adults with autism to evaluate emotional significance in speech $[81,82]$, reduce repetitive behaviors [11], and improve emotion recognition in youth $[44,83,84]$ and adults [85] with ASD.

There are many levels at which OT might impact on autism, including through the capacity to influence both sociality and to downregulate stress reactivity of the LHPA axis [27, 86]. Given that OT interacts to suppress cortisol and responses to psychosocial stress [46], and is currently being considered as a possible target treatment $[58,77,79,80]$, with potential longterm risk [87], an integrated study examining the relationship between these key regulatory hormones, cortisol, and OT was conducted.

Based in part on the previous studies reviewed, it is likely that these regulatory neurohormones, individually and collectively, contribute to the variability and severity of social stress profiles in children with ASD. Thus, the current study was designed to investigate cortisol and OT under baseline, pharmaceutical hydrocortisone challenge
(HCORT), and placebo (PLACEBO) conditions in children 8 to 12 years of age with high-functioning ASD or typical development (TD). It was hypothesized that children in both groups would show comparable baseline values of cortisol and an increase in cortisol following hydrocortisone challenge; however, it was predicted that children with ASD as a group would show greater variability in cortisol expression. In regard to OT, it was predicted that children in both groups would show comparable baseline values; however, children with TD would show an increase in OT to HCORT and a lack of change or decrease in OT to the placebo (PLACEBO). Conversely, it was predicted that children with ASD would show a lack of change or decrease in OT following both HCORT and PLACEBO suggesting that endogenous OT would fail to serve as a stress buffer. Finally, it was predicted that cortisol and OT values would be negatively and positively correlated with the social responsiveness profiles, respectively.

\section{Methods}

\section{Ethics, consent, and permission}

The Vanderbilt Institutional Review Board approved the study. Informed written consent was obtained from both parents, and assent was obtained from child participants prior to inclusion in the study.

\section{Participants}

Inclusion criteria required all participants to be free of prescribed medications and no known allergic reaction to or current use of hydrocortisone or related pharmaceutical agents. Participation in the study required three visits to the University. During visit 1 , the diagnostic and psychological measures described below were administered and the results are presented in Table 1. All enrolled participants were provided with a research letter containing the results from the standardized measures.

Inclusion in the typically developing group required an absence of any known neurological, medical, or psychiatric condition, an IQ $\geq 70$ [88], and a score $<10$ on the

Table 1 Demographic and diagnostic information for children with typical development (TD) and autism spectrum disorder (ASD)

\begin{tabular}{|c|c|c|c|c|c|c|c|}
\hline \multirow[b]{2}{*}{ Measure } & \multicolumn{2}{|l|}{ TD } & \multicolumn{2}{|l|}{ ASD } & \multirow[b]{2}{*}{ t } & \multirow[b]{2}{*}{$d f$} & \multirow[b]{2}{*}{$p$} \\
\hline & Mean & SD & Mean & SD & & & \\
\hline AGE & 9.37 & 1.58 & 9.70 & 1.93 & -0.47 & 24 & 0.64 \\
\hline ADOS & & & 13.82 & 4.56 & & & \\
\hline SCQ & 2.27 & 2.00 & 19.91 & 6.63 & -8.45 & 20 & 0.00 \\
\hline SRS & 45.82 & 6.60 & 77.73 & 12.08 & -7.69 & 20 & 0.00 \\
\hline WASI & 121.8 & 15.48 & 117.0 & 39.27 & 0.38 & 21 & 0.71 \\
\hline
\end{tabular}

ADOS Autism Diagnostic Observation Schedule, ASD autism spectrum disorder, SCQ Social Communication Questionnaire, SD standard deviation, SRS Social Responsiveness Scale, TD typical development, WASI Wechsler Abbreviated Scale of Intelligence 
Social Communication Questionnaire [89] described below. Inclusion in the ASD group required a confirmed ASD diagnosis based on the Diagnostic and Statistical Manual-5 [18] established by (1) a previous diagnosis by a psychologist, psychiatrist, or behavioral pediatrician with autism expertise; (2) current clinical judgment (BAC); and (3) corroborated by the Autism Diagnostic Observation Schedule (ADOS) [90], administered by research-reliable personnel. Participants with ASD also had to have an IQ $>70$ [88].

Independent sample $t$ tests were conducted to assess mean, standard deviations, and potential between-group differences on the demographic variables. There were no significant differences between the groups based on age or IQ (see Table 1). As expected, there were significant differences between groups on both social functioning questionnaires (i.e., SCQ and SRS).

\section{Diagnostic and psychological measures}

Autism Diagnostic Observation Schedule (ADOS [90]) is a semi-structured interview designed to assess behaviors indicative of autism. A score of $\geq 8$ on the social communication domain is required.

Wechsler Abbreviated Scale of Intelligence (WASI [88] is a measure of cognitive ability that will be used to obtain a quick, reasonable estimate of a child's intellectual functioning (IQ $\geq 70$ required).

Social Communication Questionnaire (SCQ) [89] is a screening tool for ASD. Scores of 15 or higher are highly suggestive of ASD.

The Social Responsiveness Scale (SRS) [91] is a parentreport measure covering several areas of behavior characteristics of autism with good temporal stability (males $r=.85$, females $r=.77$ ) and internal consistency (Cronbach's $\alpha>$.90).

\section{Hydrocortisone vs. placebo challenge protocol Rationale}

To specifically evaluate the relationship between cortisol and OT, participants were exposed to a single-dose hydrocortisone (pharmaceutical cortisol) challenge. Although dexamethasone has been explored in children with autism [92-95], this approach is not warranted in the current investigation. Dexamethasone is a synthetic glucocorticoid 20 to 30 times more potent than hydrocortisone that is frequently used to evaluate the function of the LHPA axis $[96,97]$. Furthermore, the actions of dexamethasone in the central nervous system are of longer duration (plasma half-life), which can result in behavioral, psychological, and cognitive changes including adverse effects [98]. For this investigation, the aim was to evaluate the relationship between hormones rather than assess the functionality of the negative feedback mechanisms of the LHPA axis. Finally, while glucocorticoids, such as hydrocortisone, can impact social behavior such as reduction in phobic social fear [99], the dose in the current study was comparatively low.

\section{Hydrocortisone study protocol}

A double-blind, placebo-controlled, randomly assigned, crossover design was employed. The protocol was conducted at the Pediatric Clinic Research Center at Vanderbilt University over two visits with 1-week intervals. The order of HCORT or PLACEBO was randomly determined by Vanderbilt Investigational Drug Service (IDS) pharmacy. The investigative team and study participants were blind to order assignment. Following a health status check by medical staff, participants were administered hydrocortisone during one visit (1) a low dose of hydrocortisone and (2) placebo administration prepared by IDS. Hydrocortisone (5 mg per $\mathrm{m} 2$ ) or placebo was administered via liquid suspension one syringe of liquid formulation $(15 \mathrm{~mL})$. Blood samples were drawn by a pediatric phlebotomist.

\section{Dose}

The dose of drug and placebo was determined by the participant's BSA. Prior to administration, height and weight were assessed to calculate body surface area $\left(\mathrm{m}^{2}\right)$ to determine appropriate hydrocortisone dose $(\mathrm{mg} /$ day) using the Mosteller method [100] BSA $\left(\mathrm{m}^{2}\right)=([\operatorname{Height}(\mathrm{cm}) \times$ Weight $(\mathrm{kg})\} / 3600)^{1 / 2}$. Children determined to be obese (have a bsa $>$ the 95th \%) were excluded from participation in the study [101]. The administration of a single dose of hydrocortisone was administered in one dose level, which is considered to be mild $\left(5 \mathrm{mg}\right.$ per $\mathrm{m}^{2}$ ) and placebo. This is considered a low level of hydrocortisone, and behavioral changes were expected to be subtle. Average pediatric doses range from 10 to $25 \mathrm{mg} /$ day [102]. In pediatric patients, the initial dose of hydrocortisone for various diseases is considerably higher than what was administered in the current study with levels ranging from 20 to $240 \mathrm{mg}$ per $\mathrm{m}^{2}$ bsa per day. Demonstrable effects are detectable within $1 \mathrm{~h}$; thus, sample collection of cortisol and OT were taken at baseline and at 60 -min post administration.

\section{Sample collection}

For each blood draw, $6 \mathrm{ml}$ was collected. Repeat blood collection occurred at (1) baseline, approximately $15 \mathrm{~min}$ after arrival and acclimation to the clinic setting and immediately before hydrocortisone/placebo administration and (2) $60 \mathrm{~min}$ after the administration of the pharmaceutical agent. Blood was collected on ice and centrifuged at $4{ }^{\circ} \mathrm{C}, 3300 \mathrm{rpm}$ for $12 \mathrm{~min}$. Plasma was then stored in a $-80{ }^{\circ} \mathrm{C}$ freezer until assay. Serum and salivary samples from 14 children with ASD (12 males, 2 females) 
and 11 neurotypical (10 males, 1 females) children were completed for hydrocortisone and placebo conditions.

\section{Oxytocin assay}

The oxytocin assay (Enzo Life Sciences, Farmingdale, NY) has been validated for various species including humans [103-105]. The assay was conducted at a dilution of 1:5 similar to other human studies. Samples were collected at approximately the same time of day (1:00 to 4:00 p.m.). The measurement of peripheral OT has been controversial, in that its levels in plasma are not always correlated with levels in cerebrospinal fluid [106, 107]. However, in many recent studies, peripheral measures have been used as a valuable reflection of OT system activity [108-110]. In addition, there is disagreement as to whether or not plasma samples should be extracted before using commercial enzyme immunoassay kits. The proponents of extraction believe that the high levels measured in unextracted samples indicate that these readings include other substances in addition to OT [111, 112]. Proponents of non-extracted samples believe that extraction removes a portion of the OT which is sequestered in plasma proteins [113]. Recent unpublished findings in mass spectrometry support this view showing high levels of OT closer to those in unextracted samples [114]. The c.v.s for assays were intra-assay, $2.45 \%$, and inter-assay, $8.61 \%$.

\section{Cortisol sample collection and assays}

Salivary cortisol collection has been previously described for home salivary samples ( $4 \times$ per day for 3 days for 2 weeks) and at arrival, baseline, 20, 40, and 60 min post stress exposure [9, 10]. Assays were performed using coated tube radioimmunoassay RIA kits (Siemens Medical Solutions Diagnostics, Los Angeles) and modified to accommodate overall lower levels of cortisol in human saliva relative to plasma.

\section{AVP assay}

The AVP assay (Enzo Life Sciences, Farmingdale, NY) was conducted at a dilution of 1.1 similar to other human studies in the lab [61] and comparable to the field which usually use dilutions between 1:1 and 1:2 [115, 116]. As noted above, samples were collected at approximately the same time of day (1:00 to 4:00 p.m.). The intra-assay cV for the AVP assay is $4.63 \%$. The inter-assay cv is $11.60 \%$.

\section{Statistical analysis}

Independent sample $t$ tests were conducted to assess mean, standard deviations, and potential between-group differences on the dependent variables. Analysis of variance (ANOVA) was the primary statistical approach to determine within and between subject effects on the dependent variables (OT, cortisol, and AVP). The ANOVA model included the within subject factors "Condition" (hydrocortisone/placebo) and "Time" (pre and post) and the between-subject factor "Group" (ASD vs. TD). Due to skewed distribution, salivary and plasma cortisol were $\log$ transformed prior to inclusion in the model. Paired sample $t$ tests were conducted to specify the meaning of statistically significant interactions involving Condition and Group. Finally, to examine the relationships between hormone concentrations and subject characteristics, Pearson product moment correlations were conducted.

\section{Results}

Using independent sample $t$ tests, there were no precondition baseline between-group differences for OT, plasma cortisol, and salivary cortisol (all $p>0.05$; see means and standard deviations in Table 2). However, there was a trend for baseline differences for AVP $t(23)=-2.01, p=$ 0.06 showing slight elevation in the ASD compared to the TD group (see Table 2).

Using ANOVA to examine Time, Condition, and Group effects, for OT, there was a significant difference for Time $F(1,23) 8.95, p=0.007)$ indicating the expected difference between pre and post for both groups based on the HCORT levels. As predicted, there was a significant Time $\times$ Condition $\times$ Group interaction $F(1.23)=4.18, p=0.05$ in OT (see Fig. 1).

Table 2 Means and standard deviations for oxytocin (OT) $(\mathrm{pg} / \mathrm{ml})$, cortisol $(\mathrm{ng} / \mathrm{ml})$, and arginine vasopressin (AVP) $(\mathrm{pg} / \mathrm{ml})$ Measure

\begin{tabular}{lllll}
\hline Oxytocin & TD mean & TD SD & ASD mean & ASD SD \\
OT pre-HCORT & 2009.92 & 813.83 & 2340.36 & 1145.38 \\
OT post-HCORT & 2148.55 & 777.79 & 2140.67 & 951.47 \\
OT pre-PLACEBO & 2566.98 & 921.75 & 2199.97 & 822.24 \\
OT post-PLACEBO & 2089.01 & 670.12 & 2074.19 & 886.10 \\
Cortisol-P plasma & & & & \\
Cortisol-P pre-HCORT & 0.91 & 0.30 & 0.93 & 0.16 \\
Cortisol-P post-HCORT & 1.53 & 0.44 & 1.68 & 0.19 \\
Cortisol-P pre-PLACEBO & 0.85 & 0.13 & 0.95 & 0.11 \\
Cortisol-P post-PLACEBO & 0.75 & 0.19 & 0.91 & 0.14 \\
Cortisol-S saliva & & & & \\
Cortisol-S pre-HCORT & 0.91 & 0.30 & 0.93 & 0.16 \\
Cortisol-S post-HCORT & 1.54 & 0.44 & 1.68 & 0.19 \\
Cortisol-S pre-PLACEBO & 0.85 & 0.13 & 0.95 & 0.11 \\
Cortisol-S post-PLACEBO & 0.75 & 0.19 & 0.91 & 0.14 \\
Arginine vasopressin AVP & & & & \\
AVP pre-HCORT & 1.94 & 0.26 & 2.16 & 0.28 \\
AVP post-HCORT & 2.05 & 0.27 & 2.12 & 0.19 \\
AVP pre-PLACEBO & 1.98 & 0.24 & 2.23 & 0.28 \\
AVP post-PLACEBO & 2.11 & 0.37 & 2.14 & 0.32 \\
\hline
\end{tabular}




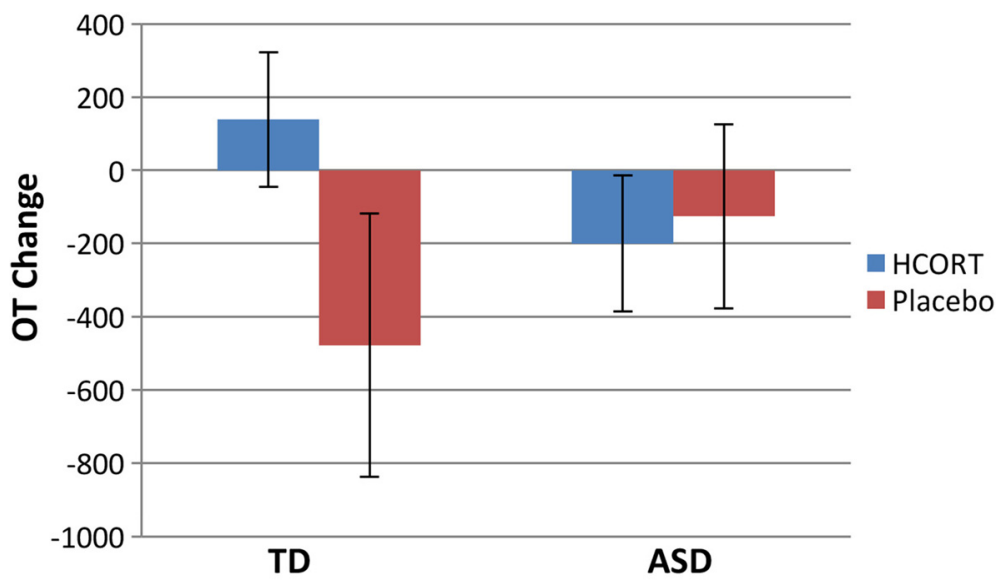

Fig. 1 Mean oxytocin change across conditions (hydrocortisone and placebo) and group (ASD and TD). The mean OT change between post minus prehydrocortisone (HCORT, blue) and placebo (red) administration between children with ASD and TD. In the TD group, there was a significant change in OT during HCORT compared to placebo condition. In contrast, the ASD group did not show a significant change in OT between the conditions

To examine Condition effects, we conducted a paired $t$ test on the change scores of OT between conditions by each group. There was a Condition effect in the TD group (mean condition differences $=616.6 ; \mathrm{SD}=929.89, t(10)=$ 2.0; $p=.05$ ), but not in the ASD group (mean condition differences $=-73.91, \mathrm{SD}=760.56, t(13)=-.36, p=.72)$. Given that the condition difference was in opposite directions between diagnostic groups, it is clear that the condition effect is significantly different between diagnostic groups.

Using ANOVA, the AVP results revealed no Time effect $F(1,23) 0.23, p=0.64$. Moreover, there was no Time $\times$ Group $F(1,23) 2.52, p=0.13$, Condition $\times$ Group $F(1,23)$ $0.80, p=0.78$ or Time $\times$ Condition $\times$ Group interaction $F(1,23) 0.26, p=0.62$.

Additional statistical approaches were employed to further explore the measurement and change of cortisol. Since hydrocortisone is pharmaceutical cortisol, analyses focused on confirming expected differences across the conditions and demonstrating the strong relationships between plasma and salivary cortisol. Paired sample $t$ tests of logged data showed a significant difference in plasma cortisol $t(24)-8.21, p=0.001$, and salivary cortisol $t(24)$ -8.23, $p=0.001$ following HCORT indicating an expected rise in circulating cortisol in response to administration of hydrocortisone. However, there was not a significant difference in cortisol following PLACEBO $t(24), 1.82, p=$ 0.08 . Thus, plasma and salivary cortisol rose in response to the pharmaceutical challenge but remained unchanged showing comparable values across the groups for the PLACEBO condition (see Fig. 2).

Levene's Test for Equality of Variances was used to examine variability for each of the hormones. Results revealed a significant difference for cortisol plasma HCORT
$F(1,23)=4.31, p=0.05$; however, there were no significant between-group differences on the salivary cortisol, OT, or AVP levels.

Pearson product moment correlations were conducted to examine associations between the hormones. For the total sample, plasma and salivary cortisol were highly correlated $r=.99, p=0.001$, as expected. There were no significant correlations between OT, cortisol, and AVP during baseline, pharmaceutical challenge, or placebo (all $p>0.05$ ). In regard to within-group correlations, for the ASD group, the only significant comparison was OT and cortisol following HCORT $r=-.47, p=0.05$. As Fig. 1 illustrates, the two groups showed opposing directional effects. For the TD group, the only significant correlation was between OT and cortisol at baseline $r=.53, p=0.05$ (see Fig. 3).

In regard to hormone levels and symptom profile, there were a few correlations. In the TD group, the SRS (impairment scale of social functioning) was positively associated with baseline plasma cortisol $(r=.68, p=0.02)$ and AVP $(p=0.03)$. In the ASD group, there was a modest negative trend for the SRS and AVP baseline $(r=-.54,0.08)$. There were no significant correlations between the SRS and post hydrocortisone or placebo administration (all $p>0.05$ ).

\section{Discussion}

The current study was designed to investigate cortisol, OT, and AVP under baseline, pharmaceutical HCORT, and PLACEBO conditions in children with ASD and TD. In regard to OT, it was predicted that children in both groups would show comparable baseline values; however, children with TD would show an increase in OT to HCORT and a decrease in OT to the PLACEBO. Conversely, it was predicted that children with ASD would show a decrease in 


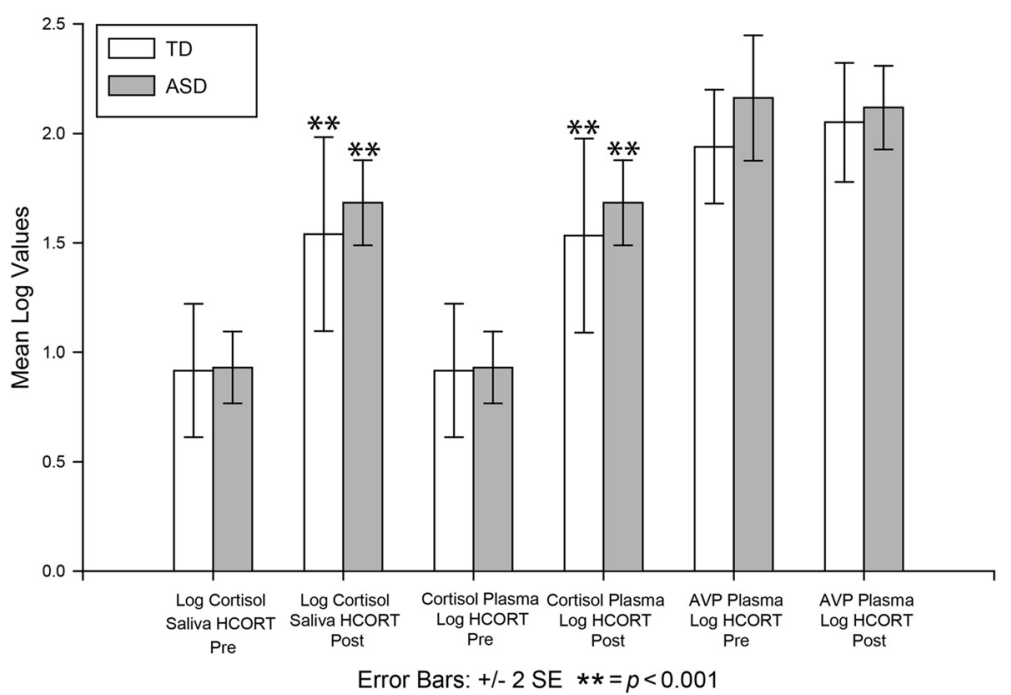

Fig. 2 Levels pre- and posthydrocortisone (HCORT) challenge across groups. The mean log salivary and plasma cortisol and plasma arginine vasopressin (AVP) are shown for pre- and post-HCORT administration in children with typical development (TD; white) and autism spectrum disorder (ASD; gray)

OT following both HCORT and PLACEBO suggesting that endogenous OT would fail to serve as a stress buffer. Finally, it was predicted that cortisol and OT values would be negatively and positively correlated with the social responsiveness profiles, respectively.

There were no between-group baseline differences for OT which do not support the oxytocin-deficit hypothesis model in autism $[40,67,117]$ as children with and without ASD showed comparable baseline OT plasma concentration prior to HCORT and PLACEBO supporting our hypothesis. There were also no significant differences in AVP, which is similar to Miller and colleagues [61] that challenged the prevalent notion that these neuropeptides are lower in children and adolescents with

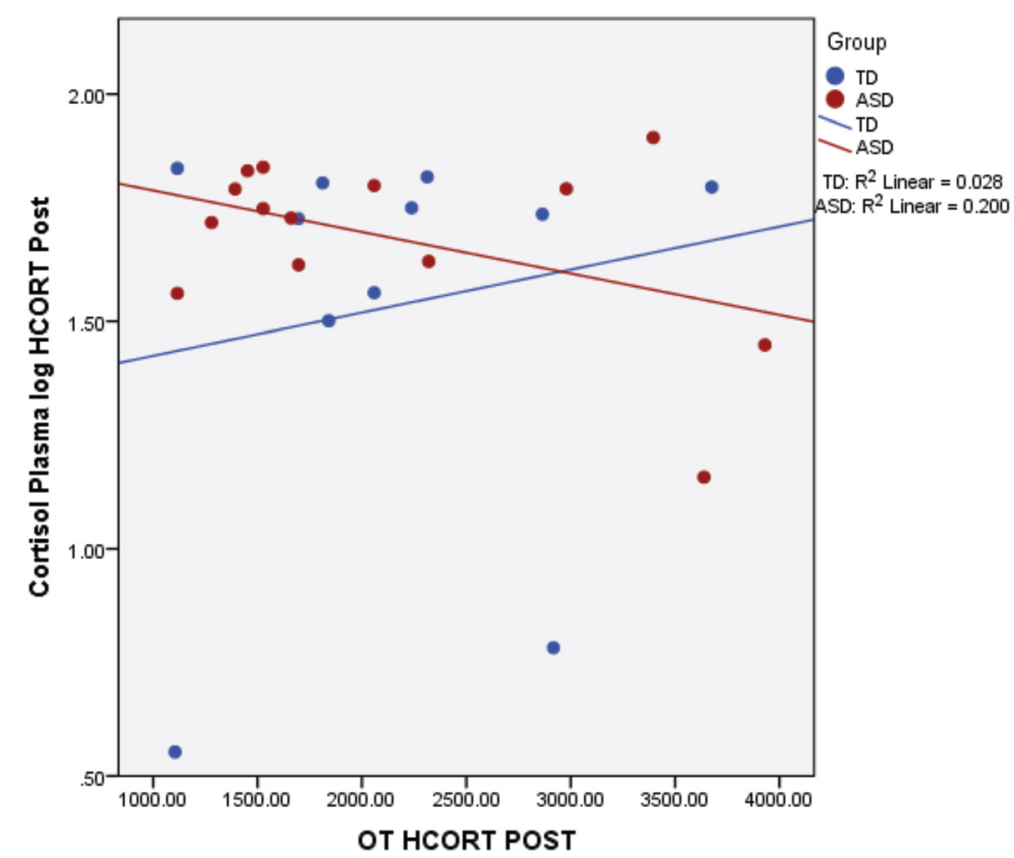

Fig. 3 Correlations between plasma cortisol and oxytocin (OT) following administration of hydrocortisone (HCORT) in children with TD (blue) and ASD (red). As shown, there are opposing relationships between the groups. Within-group correlations in the ASD children revealed a negative correlation between OT and cortisol following HCORT administration 
ASD. The findings are also in agreement with Parker and colleagues [118] that showed no baseline plasma differences in OT in a large sample of participants indicating similar circulating concentration between children with ASD and non-ASD children.

Following the administration of hydrocortisone, an inverse relationship was observed for the typically developing children such that OT increased during physiological challenge and remained stable or decreased during placebo administration. As predicted, these findings suggest that OT played a stress-buffering role during cortisol administration. The decrease in OT during the placebo condition supports the idea that the lab procedures were not inherently stress producing. Yet for the ASD group, OT remained stable or decreased during both the physiological challenge and the placebo condition, suggesting that OT failed to serve as a stress buffer under conditions of physiological stress.

While OT has been tied to the social ability of children with ASD [119], the diminished moderating effect of OT may play a contributory role in the heightened stress often observed in children with ASD especially during social interactions [1-3]. In other words, in addition to experiencing heightened stress in response to novel and changing situations, it appears that oxytocin does not assist in ameliorating stress once activated. Thus, the results contribute to the growing complexity in our understanding of the effects of OT on social behavior including individuals on the autism spectrum [87].

Even though AVP is structurally similar to OT, there were no significant differences between the groups, over time, or across conditions. Additionally, there were no significant correlations between AVP and the other hormones. It is important to note that there was significant variability in the samples, especially in the TD group during the placebo condition. It is possible that this larger variability and rather small sample size may have prevented the detection of plausible differences.

It was hypothesized that children in both groups would show comparable baseline values of cortisol and an expected increase following HCORT, which was supported. Participants evidenced a significant rise in both plasma and salivary cortisol following the hydrocortisone challenge, which was not demonstrated in the placebo condition. Therefore, children with and without ASD showed an adaptive rise in peripheral concentrations of cortisol following controlled pharmaceutical administration suggesting no systemic dysregulation of the LHPA axis under such conditions.

Previous studies have shown a tendency for greater variability in the expression of cortisol in children with ASD [1, 3]. While the current findings showed significant variability in plasma cortisol following the administration of hydrocortisone, it was observed in the TD not the ASD group. It may be the case that context and the type of stressor play an important role in the individual expression of cortisol between and within groups as has been previously suggested $[1,3]$.

In addition to the primary analyses described above, associations between the hormones were explored. While there was an inverse relationship between OT and cortisol following the administration of hydrocortisone in the ASD group, it did not reach significance. Nevertheless, it appears to be consistent with the observed interaction between the groups, time, and condition such that the children with ASD seemed to show a down regulation of OT when physiologically challenged which was opposite of the TD group. There was also a trend level positive correlation at baseline between cortisol and OT suggesting the expected synergistic relationship between arousal and stress buffering between these hormones.

The current study induced a stress response via pharmaceutical challenge therefore removing individual differences based on perceived stress. This allowed for the examination of regulatory hormonal response under carefully controlled dose and response conditions without the impact of influential processive factors [13]. Moreover, the randomized, double-blind, crossover design limited bias and enabled direct comparison between the participants across comparable physiological conditions. As a result, alternative explanations not related to the experimental condition (HCORT) such as history, testing, or statistical effects (e.g., regression to the mean) [120] were minimized or removed. To our knowledge, this is the first experiment in which cortisol levels were experimentally manipulated in order to methodically examine the regulation of oxytocin during stress induction.

Despite the strengths of the study, there are limitations to acknowledge. Most notably, the pilot study included a rather small sample of high-functioning participants with ASD and TD within a rather narrow age range. Thus, the generalizability of the findings may be limited based on functioning level and age. We also acknowledge that the measurement of peripheral OT, AVP, and cortisol is only a proxy for underlying regulatory processes. The extent to which these peripheral hormones individually and collectively represent the underlying physiological complexity is unclear. In particular, there remains a controversy in the field regarding OT with some proponents insisting on extraction methods [111, 112]. In consideration of this debate, our decision to not extract OT may be considered an additional limitation of the study.

\section{Conclusions}

These data build on previous models showing that the interplay between OT and stress is complex and 
influenced by many factors \{Heinrichs, 2008 \#797; Taylor, 2006 \#736; Turner, 1999 \#794\}. These findings provide the foundation and justification for future work exploring biobehavioral influences to elucidate the heterogeneity in social functioning and stress modulation in autism. Moreover, the findings emphasize the complexity of not only the social presentation of children with ASD but also the underlying associated hormonal profile that warrants critical consideration. The future study of neurohormone regulation in general, including the modulatory role of OT on physiology, is essential especially as frequent and unregulated treatment with OT is emerging [87]. Moreover, the impact of other factors, such as context and social support will be important to explore as plausible mediating variables in the complex interplay between oxytocin and cortisol regulation.

\section{Acknowledgements \\ The authors thank Deloris Lee and Veneranda Mkoma from the Pediatric Clinical Research Center at Vanderbilt for their care and expertise in implementing the pharmaceutical and phlebotomy protocols. Finally, we are grateful for the diligent oversight and guidance provided by John Oleis, D.Ph. BCNSP and team from Vanderbilt IDS pharmacy.}

\section{Funding}

This work was supported in part by a Vanderbilt Institute Clinical Translational Research (VICTR) grant VR1460 (Corbett),and supported by CTSA award No. UL1TR000445 from the National Center for Advancing Translational Sciences. Its contents are solely the responsibility of the authors and do not necessarily represent official views of the National Center for Advancing Translational Sciences or the National Institutes of Health; however, members did not contribute to the design, analysis, or interpretation of the study data. Additionally, support was provided by the National Institute of Child and Human Development (NICHD) U54 HD83211 (Vanderbilt University Medical Center).

\section{Availability of data and materials}

The de-identified data from the current study are available from the corresponding author on reasonable request.

\section{Authors' contributions}

BAC conceptualized and designed the study with $L \mathrm{M}$, confirmed diagnosis of participants, analyzed the data, and wrote the initial draft of the manuscript. KLB supervised the biological sample assays, provided hormonal expertise, contributed to data interpretation, and made significant contributions to the manuscript. KS served as the study physician, examined the research participants, assisted in the phlebotomy collection as needed, wrote the pharmaceutical orders, and contributed to the manuscript. DS acquired the majority of the participant's psychological data, assisted in the phlebotomy collection, ran the study participant protocol, monitored the study enrollment, entered the data, and made important contributions to the final manuscript. TARW ran the assays for all of the oxytocin and arginine vasopressin samples, inspected and organized all biological data values, reviewed data with $\mathrm{KB}$, and contributed to the final manuscript. LJM conceptualized and designed the study with BAC, provided expertise in biological and physiological systems, and contributed to data interpretation and completion of the manuscript. All authors read and approved the final manuscript.

\section{Competing interests}

The authors declare that they have no competing interests.

\section{Ethics approval and consent to participate}

The Vanderbilt Institutional Review Board approved the study protocol no. 100916. Informed written consent was obtained from both parents, and assent was obtained from child participants prior to inclusion in the study.

\section{Author details}

'Department of Psychiatry and Behavioral Sciences, Vanderbilt University, PMB 40, 230 Appleton Place, Nashville, TN 37203, USA. Vanderbilt Kennedy Center for Research on Human Development, Nashville, TN, USA.

${ }^{3}$ Department of Psychology, Vanderbilt University, Nasvhille, TN, USA.

${ }^{4}$ University of California, Davis, CA, USA. ${ }^{5}$ Virginia Polytechnic Institute and State University, Blacksburg, VA, USA. ${ }^{6}$ Department of Pediatrics, Perinatal Institute, Cincinnati Children's Hospital Medical Center, University of Cincinnati College of Medicine, Cincinnati, OH, USA.

Received: 7 January 2016 Accepted: 5 August 2016

Published online: 18 August 2016

\section{References}

1. Corbett BA, Schupp CW, Simon D, Ryan N, Mendoza S. Elevated cortisol during play is associated with age and social engagement in children with autism. Mol Autism. 2010:1:13.

2. Corbett BA, Swain DM, Newsom C, Wang L, Song Y, Edgerton D. Biobehavioral profiles of arousal and social motivation in autism spectrum disorders. J Child Psychol Psychiatry. 2014;55:924-34.

3. Schupp CW, Simon D, Corbett BA. Cortisol responsivity differences in children with autism spectrum disorders during free and cooperative play. J Autism Dev Disord. 2013:43(10):2405-17.

4. Charmandari E, Kino T, Souvatzoglou E, Chrousos GP. Pediatric stress: hormonal mediators and human development. Horm Res. 2003;59:161-79.

5. Corbett BA, Schupp CW, Lanni KE. Comparing biobehavioral profiles across two social stress paradigms in children with and without autism spectrum disorders. Mol Autism. 2012;3:13.

6. Cardoso C, Kingdon D, Ellenbogen MA. A meta-analytic review of the impact of intranasal oxytocin administration on cortisol concentrations during laboratory tasks: moderation by method and mental health. Psychoneuroendocrinology. 2014;49:161-70.

7. Kanner L. Autistic disturbances of affective contact. Nervous Child. 1943:2:217-50.

8. Carter CS. Sex differences in oxytocin and vasopressin: implications for autism spectrum disorders? Behav Brain Res. 2007;176:170-86.

9. Corbett BA, Mendoza S, Abdullah M, Wegelin JA, Levine S. Cortisol circadian rhythms and response to stress in children with autism. Psychoneuroendocrinology. 2006;31:59-68.

10. Corbett BA, Mendoza S, Wegelin JA, Carmean V, Levine S. Variable cortisol circadian rhythms in children with autism and anticipatory stress. J Psychiatr Neurosci. 2008;33:227-34.

11. Hollander E, Novotny S, Hanratty M, Yaffe R, DeCaria CM, Aronowitz BR, Mosovich S. Oxytocin infusion reduces repetitive behaviors in adults with autistic and Asperger's disorders. Neuropsychopharmacology. 2003;28:193-8,

12. Insel TR, O'Brien DJ, Leckman JF. Oxytocin, vasopressin, and autism: is there a connection? Biol Psychiatry. 1999;45:145-57.

13. Herman JP, Cullinan WE. Neurocircuitry of stress: central control of the hypothalamo-pituitary-adrenocortical axis. Trends Neurosci. 1997:20:78-84.

14. Sapolsky RM, Romero LM, Munck AU. How do glucocorticoids influence stress responses? Integrating permissive, suppressive, stimulatory, and preparative actions. Endocr Rev. 2000;7:284-301.

15. Hennessey JW, Levine S. Stress, arousal, and the pituitary-adrenal system: a psychoendocrine hypothesis. New York: Academic; 1979.

16. Levine S. The influence of social factors on the response to stress. Psychother Psychosom. 1993;60:33-8.

17. Mendoza SP, Capitanio JP, Mason WA. Chronic social stress: studies in non-human primates. In: Mench GPMJA, editor. Biology of Animal Stress Basic Principles and Implications for Animal Welfare. New York: CABI Publishing; 2000. p. 227-47.

18. APA. Diagnostic and Statistical Manual of Mental Disorders, Fifth Edition (DSM-5). Washinton: American Psychiatric Association; 2013.

19. Richdale AL, Prior MR. Urinary cortisol circadian rhythm in a group of high-functioning children with autism. J Autism Dev Disord. 1992;22:433-47. 
20. Spratt EG, Nicholas JS, Brady KT, Carpenter LA, Hatcher CR, Meekins KA, Furlanetto RW, Charles JM. Enhanced cortisol response to stress in children in autism. J Autism Dev Disord. 2012;42:75-81.

21. Tordjman S, Anderson GM, McBride PA, Hertzig ME, Snow ME, Hall LM, Thompson SM, Ferrari P, Cohen DJ. Plasma beta-endorphin, adrenocorticotropin hormone, and cortisol in autism. J Child Psychol Psychiatry. 1997;38:705-15.

22. Lopata C, Volker MA, Putnam SK, Thomeer ML, Nida RE. Effect of social familiarity on salivary cortisol and self-reports of social anxiety and stress in children with high functioning autism spectrum disorders. J Autism Dev Disord. 2008;38:1866-77.

23. Naber FB, Swinkels SH, Buitelaar JK, Bakermans-Kranenburg MJ, Van IMH, Dietz $\mathrm{C}$, van Daalen $\mathrm{E}$, van Engeland $\mathrm{H}$. Attachment in toddlers with autism and other developmental disorders. J Autism Dev Disord. 2007;37:1123-38.

24. Bitsika V, Sharpley CF, Sweeney JA, McFarlane JR. HPA and SAM axis responses as correlates of self- vs parental ratings of anxiety in boys with an Autistic Disorder. Physiol Behav. 2014;127:1-7.

25. Simon DM, Corbett BA. Examining associations between anxiety and cortisol in high functioning male children with autism. J Neurodev Disord. 2013;5:32.

26. Taylor JL, Corbett BA. A review of rhythm and responsiveness of cortisol in individuals with autism spectrum disorders. Psychoneuroendocrinology. 2014:49C:207-28.

27. Carter CS. Neuroendocrine perspectives on social attachment and love. Psychoneuroendocrinology. 1998;23:779-818.

28. Carter CS, Grippo AJ, Pournajafi-Nazarloo H, Ruscio MG, Porges SW. Oxytocin, vasopressin and sociality. Prog Brain Res. 2008;170:331-6.

29. Bales KL, Carter CS. Developmental exposure to oxytocin facilitates partner preferences in male prairie voles (Microtus ochrogaster). Behav Neurosci. 2003;117:854-9.

30. Bales KL, Kim AJ, Lewis-Reese AD, Sue Carter C. Both oxytocin and vasopressin may influence alloparental behavior in male prairie voles. Horm Behav. 2004;45:354-61

31. Winslow JT, Shapiro L, Carter CS, Insel TR. Oxytocin and complex social behavior: species comparisons. Psychopharmacol Bull. 1993;29:409-14.

32. Young $L$, Wang Z, Insel TR. Neuroendocrine bases of monogamy. Trends Neurosci. 1998;21:71-5.

33. Kirsch $P$, Esslinger $C$, Chen $Q$, Mier D, Lis S, Siddhanti S, Gruppe H, Mattay VS, Gallhofer B, Meyer-Lindenberg A. Oxytocin modulates neural circuitry for social cognition and fear in humans. J Neurosci. 2005;25:11489-93.

34. Kosfeld M, Heinrichs M, Zak PJ, Fischbacher U, Fehr E. Oxytocin increases trust in humans. Nature. 2005;435:673-6.

35. Teng BL, Nonneman RJ, Agster KL, Nikolova VD, Davis TT, Riddick NV, Bake LK, Pedersen CA, Jarstfer MB, Moy SS. Prosocial effects of oxytocin in two mouse models of autism spectrum disorders. Neuropharmacology. 2013;72:187-96.

36. Neumann ID. Involvement of the brain oxytocin system in stress coping: interactions with the hypothalamo-pituitary-adrenal axis. Prog Brain Res. 2002;139:147-62.

37. Neumann ID, Kromer SA, Toschi N, Ebner K. Brain oxytocin inhibits the (re)activity of the hypothalamo-pituitary-adrenal axis in male rats: involvement of hypothalamic and limbic brain regions. Regul Pept. 2000;96:31-8.

38. Dayas CV, Buller KM, Day TA. Neuroendocrine responses to an emotional stressor: evidence for involvement of the medial but not the central amygdala. Eur J Neurosci. 1999;11:2312-22.

39. Domes G, Heinrichs M, Glascher J, Buchel C, Braus DF, Herpertz SC. Oxytocin attenuates amygdala responses to emotional faces regardless of valence. Biol Psychiatry. 2007;62:1187-90.

40. Duhamel JR, Zalla T, Herbrecht E, Leboyer M, Sirigu A. Promoting social behavior with oxytocin in high-functioning autism spectrum disorders. Proc Natl Acad Sci U S A. 2010;107:4389-94.

41. Ashwin C, Baron-Cohen S, Wheelwright S, O'Riordan M, Bullmore ET. Differential activation of the amygdala and the 'social brain' during fearful face-processing in Asperger Syndrome. Neuropsychologia. 2007;45:2-14.

42. Baron-Cohen S, Ring HA, Bullmore ET, Wheelwright S, Ashwin C, Williams SC. The amygdala theory of autism. Neurosci Biobehav Rev. 2000;24:355-64.

43. Corbett BA, Carmean V, Ravizza S, Wendelken C, Henry ML, Carter C, Rivera SM. A functional and structural study of emotion and face processing in children with autism. Psychiatry Res. 2009;173(3):196-205.
44. Guastella AJ, Einfeld SL, Gray KM, Rinehart NJ, Tonge BJ, Lambert TJ, Hickie IB. Intranasal oxytocin improves emotion recognition for youth with autism spectrum disorders. Biol Psychiatry. 2010;67:692-4.

45. Ditzen B, Schaer M, Gabriel B, Bodenmann G, Ehlert U, Heinrichs M. Intranasal oxytocin increases positive communication and reduces cortisol levels during couple conflict. Biol Psychiatry. 2009;65:728-31.

46. Heinrichs M, Baumgartner T, Kirschbaum C, Ehlert U. Social support and oxytocin interact to suppress cortisol and subjective responses to psychosocial stress. Biol Psychiatry. 2003;54:1389-98.

47. Quirin M, Kuhl J, Dusing R. Oxytocin buffers cortisol responses to stress in individuals with impaired emotion regulation abilities. Psychoneuroendocrinology. 2011;36:898-904.

48. Heinrichs M, Meinlschmidt G, Neumann I, Wagner S, Kirschbaum C, Ehlert U, Hellhammer DH. Effects of suckling on hypothalamic-pituitary-adrenal axis responses to psychosocial stress in postpartum lactating women. J Clin Endocrinol Metab. 2001;86:4798-804.

49. Baumgartner T, Heinrichs M, Vonlanthen A, Fischbacher U, Fehr E. Oxytocin shapes the neural circuitry of trust and trust adaptation in humans. Neuron. 2008:58:639-50.

50. Green JJ, Hollander E. Autism and oxytocin: new developments in translational approaches to therapeutics. Neurotherapeutics. 2010;7:250-7.

51. Heinrichs M, Gaab J. Neuroendocrine mechanisms of stress and social interaction: implications for mental disorders. Curr Opin Psychiatry. 2007;20:158-62.

52. Goldman M, Marlow-O'Connor M, Torres I, Carter CS. Diminished plasma oxytocin in schizophrenic patients with neuroendocrine dysfunction and emotional deficits. Schizophr Res. 2008;98:247-55.

53. Legros JJ. Inhibitory effect of oxytocin on corticotrope function in humans: are vasopressin and oxytocin ying-yang neurohormones? Psychoneuroendocrinology. 2001;26:649-55.

54. Windle RJ, Kershaw YM, Shanks N, Wood SA, Lightman SL, Ingram CD. Oxytocin attenuates stress-induced c-fos mRNA expression in specific forebrain regions associated with modulation of hypothalamo-pituitaryadrenal activity. J Neurosci. 2004;24:2974-82.

55. Chen FS, Kumsta R, von Dawans B, Monakhov M, Ebstein RP, Heinrichs M. Common oxytocin receptor gene (OXTR) polymorphism and social support interact to reduce stress in humans. Proc Natl Acad Sci U S A. 2011;108:19937-42.

56. Turner RA, Altemus M, Enos T, Cooper B, McGuinness T. Preliminary research on plasma oxytocin in normal cycling women: investigating emotion and interpersonal distress. Psychiatry. 1999;62:97-113.

57. Taylor SE, Gonzaga GC, Klein LC, Hu P, Greendale GA, Seeman TE. Relation of oxytocin to psychological stress responses and hypothalamic-pituitaryadrenocortical axis activity in older women. Psychosom Med. 2006;68:238-45.

58. Heinrichs M, Domes G. Neuropeptides and social behaviour: effects of oxytocin and vasopressin in humans. Prog Brain Res. 2008;170:337-50.

59. Insel TR. A neurobiological basis of social attachment. Am J Psychiatry. 1997;154:726-35.

60. Jacob S, Brune CW, Carter CS, Leventhal BL, Lord C, Cook Jr EH. Association of the oxytocin receptor gene (OXTR) in Caucasian children and adolescents with autism. Neurosci Lett. 2007;417:6-9.

61. Miller M, Bales KL, Taylor SL, Yoon J, Hostetler CM, Carter CS, Solomon M. Oxytocin and vasopressin in children and adolescents with autism spectrum disorders: sex differences and associations with symptoms. Autism Res. 2013;6:91-102.

62. Skuse D, Gallagher L. Dopaminergic-neuropeptide interactions in the social brain. Trends Cogn Sci. 2009;13:27-35.

63. Welch MG, Ruggiero DA. Predicted role of secretin and oxytocin in the treatment of behavioral and developmental disorders: implications for autism. Int Rev Neurobiol. 2005;71:273-315.

64. Young LJ, Pitkow LJ, Ferguson JN. Neuropeptides and social behavior: animal models relevant to autism. Mol Psychiatry. 2002;7 Suppl 2:S38-9.

65. Feldman R, Golan O, Hirschler-Guttenberg Y, Ostfeld-Etzion S, Zagoory-Sharon O. Parent-child interaction and oxytocin production in pre-schoolers with autism spectrum disorder. Br J Psychiatry. 2014;205:107-12.

66. Green L, Fein D, Modahl C, Feinstein C, Waterhouse L, Morris M. Oxytocin and autistic disorder: alterations in peptide forms. Biol Psychiatry. 2001;50:609-13.

67. Green L, Fein D, Morris M, Waterhouse L, Feinstein C, Levin H. Plasma oxytocin levels in autistic children. Biol Psychiatry. 1998;43:270-7. 
68. Taurines R, Schwenck C, Lyttwin B, Schecklmann M, Jans T, Reefschlager $L$, Geissler J, Gerlach M, Romanos M. Oxytocin plasma concentrations in children and adolescents with autism spectrum disorder: correlation with autistic symptomatology. Atten Defic Hyperact Disord. 2014;6:231-9.

69. Gregory SG, Connelly JJ, Towers AJ, Johnson J, Biscocho D, Markunas CA, Lintas C, Abramson RK, Wright HH, Ellis P, et al. Genomic and epigenetic evidence for oxytocin receptor deficiency in autism. BMC Med. 2009;7:62.

70. Lerer E, Levi S, Salomon S, Darvasi A, Yirmiya N, Ebstein RP. Association between the oxytocin receptor (OXTR) gene and autism: relationship to Vineland Adaptive Behavior Scales and cognition. Mol Psychiatry. 2008;13:980-8.

71. Wermter AK, Kamp-Becker I, Hesse P, Schulte-Korne G, Strauch K, Remschmidt $\mathrm{H}$. Evidence for the involvement of genetic variation in the oxytocin receptor gene (OXTR) in the etiology of autistic disorders on high-functioning level. Am J Med Genet B Neuropsychiatr Genet. 2009;153B(2):629-39.

72. Wu S, Jia M, Ruan Y, Liu J, Guo Y, Shuang M, Gong X, Zhang Y, Yang X, Zhang D. Positive association of the oxytocin receptor gene (OXTR) with autism in the Chinese Han population. Biol Psychiatry. 2005:58:74-7.

73. Yrigollen CM, Han SS, Kochetkova A, Babitz T, Chang JT, Volkmar FR, Leckman JF, Grigorenko EL. Genes controlling affiliative behavior as candidate genes for autism. Biol Psychiatry. 2008;63:911-6.

74. Ebstein RP, Knafo A, Mankuta D, Chew SH, Lai PS. The contributions of oxytocin and vasopressin pathway genes to human behavior. Horm Behav. 2012;61:359-79.

75. Egawa J, Watanabe Y, Endo T, Tamura R, Masuzawa N, Someya T. Association between OXTR and clinical phenotypes of autism spectrum disorders. Psychiatry Res. 2013;208:99-100

76. Aoki Y, Watanabe T, Abe O, Kuwabara H, Yahata N, Takano Y, Iwashiro N, Natsubori T, Takao H, Kawakubo Y, et al. Oxytocin's neurochemical effects in the medial prefrontal cortex underlie recovery of task-specific brain activity in autism: a randomized controlled trial. Mol Psychiatry. 2015;20:447-53.

77. Bartz JA, Hollander E. Oxytocin and experimental therapeutics in autism spectrum disorders. Prog Brain Res. 2008;170:451-62

78. Gordon I, Vander Wyk BC, Bennett RH, Cordeaux C, Lucas MV, Eilbott JA, Zagoory-Sharon O, Leckman JF, Feldman R, Pelphrey KA. Oxytocin enhances brain function in children with autism. Proc Natl Acad Sci U S A. 2013:110:20953-8.

79. Neumann ID. Brain oxytocin: a key regulator of emotional and social behaviours in both females and males. J Neuroendocrinol. 2008:20:858-65.

80. Posey DJ, Erickson CA, McDougle CJ. Developing drugs for core social and communication impairment in autism. Child Adolesc Psychiatr Clin N Am. 2008;17:787-801.

81. Anagnostou E, Soorya L, Chaplin W, Bartz J, Halpern D, Wasserman S, Wang AT, Pepa L, Tanel N, Kushki A, Hollander E. Intranasal oxytocin versus placebo in the treatment of adults with autism spectrum disorders: a randomized controlled trial. Mol Autism. 2012;3:16.

82. Hollander E, Bartz J, Chaplin W, Phillips A, Sumner J, Soorya L, Anagnostou E, Wasserman S. Oxytocin increases retention of social cognition in autism. Biol Psychiatry. 2007;61:498-503.

83. Aoki Y, Yahata N, Watanbe T, Takano Y, Yuki K, Kuwabara H, Yamasue H. Oxytocin improves behavioral and neural deficits in inferring others' social emotions in autism. Brain. 2014:137:3073-86.

84. Domes G, Lischke A, Berger C, Grossmann A, Hauenstein K, Heinrichs M, Herpertz SC. Effects of intranasal oxytocin on emotional face processing in women. Psychoneuroendocrinology. 2010;35:83-93.

85. Marsh AA, Yu HH, Pine DS, Blair RJ. Oxytocin improves specific recognition of positive facial expressions. Psychopharmacology (Berl). 2010;209:225-32.

86. Neumann ID, Toschi N, Ohl F, Torner L, Kromer SA. Maternal defence as an emotional stress or in female rats: correlation of neuroendocrine and behavioural parameters and involvement of brain oxytocin. Eur J Neurosci. 2001;13:1016-24.

87. Bales KL, Solomon M, Jacob S, Crawley JN, Silverman JL, Larke RH, Sahagun E, Puhger KR, Pride MC, Mendoza SP. Long-term exposure to intranasal oxytocin in a mouse autism model. Transl Psychiatry. 2014;4:e480.

88. Wechsler D. Wechsler Abbreviated Scale of Intelligence. San Antonio: Psychological Corporation; 1999.

89. Rutter M, Bailey A, Lord C. The Social Communication Questionnaire. Los Angeles: Western Psychological Services; 2003.

90. Lord C, Risi S, Lambrecht L, Cook Jr EH, Leventhal BL, DiLavore PC, Pickles A Rutter M. The autism diagnostic observation schedule-generic: a standard measure of social and communication deficits associated with the spectrum of autism. J Autism Dev Disord. 2000;30:205-23.
91. Constantino JN, Gruber CP. Social Responsiveness Scale. Los Angeles: Western Psychological Services; 2005

92. Hoshino Y, Ohno Y, Murata S, Yokoyama F, Kaneko M, Kumashiro H. Dexamethasone suppression test in autistic children. Folia Psychiatr Neurol Jpn. 1984;38:445-9.

93. Hoshino Y, Yokoyama F, Watanabe M, Murata S, Kaneko M, Kumashiro H. The diurnal variation and response to dexamethasone suppression test of saliva cortisol level in autistic children. Jpn J Psychiatry Neurol. 1987;41:227-35.

94. Jensen JB, Realmuto GM, Garfinkel BD. The dexamethasone suppression test in infantile autism. J Am Acad Child Psychiatry. 1985;24:263-5.

95. Marinovic-Curin J, Marinovic-Terzic I, Bujas-Petkovic Z, Zekan L, Skrabic V, Dogas Z, Terzic J. Slower cortisol response during ACTH stimulation test in autistic children. Eur Child Adolesc Psychiatry. 2008;17:39-43.

96. Mager DE, Moledina N, Jusko WJ. Relative immunosuppressive potency of therapeutic corticosteroids measured by whole blood lymphocyte proliferation. J Pharm Sci. 2003;92:1521-5.

97. Steven $\mathrm{KH}$. Adrenal cortical steroids. In: Drug facts and comparisons. In: Facts and Comparisons, Inc. 5th ed. 1997. p. 122-8.

98. Fietta P, Fietta P, Delsante G. Central nervous system effects of natural and synthetic glucocorticoids. Psychiatry Clin Neurosci. 2009;63:613-22.

99. Soravia LM, Heinrichs M, Aerni A, Maroni C, Schelling G, Ehlert U, Roozendaal B, de Quervain DJ. Glucocorticoids reduce phobic fear in humans. Proc Natl Acad Sci U S A. 2006;103:5585-90.

100. Mosteller RD. Simplified calculation of body-surface area. N Engl J Med. 1987:317:1098.

101. About child and teen BMl: how is BMl calculated for children and teens? Centers for Disease Control. May 15, 2015. http://www.cdc.gov/ healthyweight/assessing/bmi/childrens_bmi/about_childrens_bmi.html

102. Winterer J, Chrousos GP, Loriaux L, Cutler GB. Effect of hydrocortisone dose schedule on adrenal steroid secretion in congenital adrenal hyperplasia. J Pediatr. 1985;106:137-42.

103. Bales KL, Kramer KM, Hostetler CM, Capitanio JP, Mendoza SP. Validation of oxytocin and vasopressin plasma assays for primates: what can blood tell us? Am J Primatol. 2005:66:73.

104. Carter CS, Pournajafi-Nazarloo H, Kramer KM, Ziegler TE, White-Traut R, Bello D, Schwertz D. Oxytocin: behavioral associations and potential as a salivary biomarker. Ann N Y Acad Sci. 2007;1098:312-22.

105. Kramer KM, Cushing BS, Carter CS, Wu J, Ottinger MA. Sex and species differences in plasma oxytocin using an enzyme immunoassay. Can J Zool. 2004:82:1194-200.

106. Kendrick KM, Keverne EB, Hinton MR, Goode JA. Cerebrospinal fluid and plasma concentrations of oxytocin and vasopressin during parturition and vaginocervical stimulation in the sheep. Brain Res Bull. 1991;26:803-7.

107. Lipari EF, Lipari D, Gerbino A, Di Liberto D, Bellafiore M, Catalano M, Valentino B. The hypothalamic magnocellular neurosecretory system in developing rats. Eur J Histochem. 2001;45:163-8.

108. Feldman R, Gordon I, Zagoory-Sharon O. Maternal and paternal plasma, salivary, and urinary oxytocin and parent-infant synchrony: considering stress and affiliation components of human bonding. Dev Sci. 2011;14:752-61.

109. Weisman O, Zagoory-Sharon O, Feldman R. Oxytocin administration to parent enhances infant physiological and behavioral readiness for social engagement. Biol Psychiatry. 2012;72:982-9.

110. Weisman O, Zagoory-Sharon O, Feldman R. Intranasal oxytocin administration is reflected in human saliva. Psychoneuroendocrinology. 2012;37:1582-6.

111. McCullough ME, Churchland PS, Mendez AJ. Problems with measuring peripheral oxytocin: can the data on oxytocin and human behavior be trusted? Neurosci Biobehav Rev. 2013;37:1485-92.

112. Robinson KJ, Hazon N, Lonergan M, Pomeroy PP. Validation of an enzyme-linked immunoassay (ELISA) for plasma oxytocin in a novel mammal species reveals potential errors induced by sampling procedure. J Neurosci Methods. 2014;226:73-9.

113. Martin WL, Carter CS. Oxytocin and vasopressin are sequestered in plasma. In: 10th World Congress of Neurohypopheseal Hormones. Bristol; 2013.

114. Brandtzaeg OK, Johnsen E, Roberg-Larsen H, Seip KF, Leknes S, Lundanes E, Wilson SR. Preprint: a robust peptidomics mass spectrometry platform for measuring oxytocin in plasma and serum. bioRxiv. 2016:042416.

115. Rubin LH, Carter CS, Bishop JR, Pournajafi-Nazarloo H, Harris MS, Hill SK, Reilly JL, Sweeney JA. Peripheral vasopressin but not oxytocin relates to severity of acute psychosis in women with acutely-ill untreated first-episode psychosis in women with acutely-ill untreated first-episode psychosis. Schizophr Res. 2013;146:138-43. 
116. Rubin LH, Carter CS, Bishop JR, Pournajafi-Nazarloo H, Drogos LL, Hill SK, Ruocco AC, Keedy SK, Reilly JL, Keshavan MS, et al. Reduced levels of vasopressin and reduced behavioral modulation of oxytocin in psychotic disorders. Schizophr Bull. 2014;40:1374-84.

117. Al-Ayadi, LY. Altered oxytocin and vasopressin levels in autistic children in Central Saudi Arabia. Neurosciences (Riyadh). 2005;10(1):47-50.

118. Parker KJ, Garner JP, Libove RA, Hyde SA, Hornbeak KB, Carson DS, Liao CP, Phillips JM, Hallmayer JF, Hardan AY. Plasma oxytocin concentrations and OXTR polymorphisms predict social impairments in children with and without autism spectrum disorder. Proc Natl Acad Sci U S A. 2014;111:12258-63.

119. Auyeung B, Lombardo MV, Heinrichs M, Chakrabarti B, Sule A, Deakin JB, Bethlehem RA, Dickens L, Mooney N, Sipple JA, et al. Oxytocin increases eye contact during a real-time, naturalistic social interaction in males with and without autism. Transl Psychiatry. 2015;5:e507.

120. Campbell DT, Stanley JC. Experimental and quasi-experimental designs for research. Geneva: Houghton Mifflin Company; 1963.

\section{Submit your next manuscript to BioMed Central} and we will help you at every step:

- We accept pre-submission inquiries

- Our selector tool helps you to find the most relevant journal

- We provide round the clock customer support

- Convenient online submission

- Thorough peer review

- Inclusion in PubMed and all major indexing services

- Maximum visibility for your research

Submit your manuscript at www.biomedcentral.com/submit 